\title{
HOW SOCIAL MEDIA \& TECHNOLOGY ARE CHALLENGING JOURNALISTS' PERCEPTIONS OF THEIR ROLE
}

Professional ideology and newsroom culture have become deeply embedded and codified in Anglo-American journalism since the late $19^{\text {th }}$ Century. Despite constant questioning by professionals and scholars alike, they have remained remarkably stable, resisting the repeated challenge of technological, societal and cultural change ranging from the groundbreaking introduction of radio and television to the 'New Journalism' of the 1960s \& 70s and the birth of the Internet. The antagonism between professional journalists and the boundaries they are erecting to distinguish themselves from 'citizen journalists', or those they regard as 'amateurs, ' is arguably reinforcing existing ideology. There are also clear signs that media outlets are unwilling to give up their traditional 'gate keeping' role. But are there other disruptive factors ushered in by the social media revolution that may finally lead to a breakdown of these norms? Using a qualitative research methodology involving semistructured interviews with journalists from leading established news outlets, this paper examines two changes to practice now becoming commonplace in the newsroom. Firstly, it explores the growing requirement for journalists to use Twitter and other social media tools to promote their own news output or their news organisation; and secondly it examines the introduction of social media 'hubs' in which journalists trawl the Internet for user-generated content to complement their own. To what extent are these two developments changing journalists' perception of their role and the culture of the newsroom? And is the broadly consensual view of their professional ideology becoming more diffuse?

KEYWORDS: Journalism, objectivity; social media; Twitter; user-generated content, boundary work

Author:

Professor Stephen Jukes

Affiliation:

Faculty of Media \& Communication

Bournemouth University

Contact details: $\quad$ sjukes@,bournemouth.ac.uk

Tel: 07990560230 
"By all means, explore ways in which social media can help you do your job. But before you tweet or post, consider how what you're doing will reflect on your professionalism and our collective reputation." - Reuters editorial advice to journalists in guidelines on the use of social media.

\section{Introduction}

It had been relatively simple and coherent. By the 1930s, the discipline of journalism had been codified as a profession; stable values, principles and practices had been established across many diverse nations and cultures, particularly within the powerful and dominant Anglo-American news industry. In short, from its origins as a profession in the late $19^{\text {th }}$ Century journalism enjoyed a long and stable development (Deuze \& Witschge 2017: 2). But the past decades of regulatory and social media disruption have fragmented that monolithic culture as the prevailing objectivity paradigm that captured many of journalism's core values has been subjected to increasingly robust - and virulent - challenge. The result has been growing antagonism between many professional journalists fighting a rear-guard action to protect their boundaries and the 'citizen journalists', bloggers and purveyors of social media who maintain that traditional journalism is failing the public.

That antagonism, often analysed by journalism scholars and discussed by journalists amongst themselves, has suddenly burst into the public spotlight following the tumultuous U.S. election campaign that saw Donald Trump installed in the White House and the controversial UK referendum over membership of the European Union. Partisan and populist reporting of both campaigns and a furore over the phenomenon of fake news have been accompanied by an unprecedented decline in public trust of traditional media organisations. That spilled over in June 2017 when journalists sent to cover the Grenfell Tower disaster in London ${ }^{1}$ were roundly abused by local residents as representing news outlets which were seen as aloof and disconnected from the social deprivation of their readers and viewers. The veteran Channel 4 news presenter Jon Snow later conceded that he and others in the media

\footnotetext{
${ }^{1}$ The 24-storey Grenfell Tower block of social housing flats caught fire in June 2017 and was quickly engulfed in flames. Aftter months of uncertainty, the final death toll was put at 71 .
} 
had become too far removed from ordinary people's lives and were too comfortable with the elite (2017).

It has been argued that the social media revolution of the past decade has rendered the boundaries of professional journalism more porous, leading to consideration of whether they should be re-conceptualised in the light of today's social media ecology (Anderson et al. 2014; Singer 2015). But there are also signs that the battle lines have in fact become further hardened in the wake of the outrage over fake news. In an attempt to win back public trust, many established or 'legacy' news organisations such as the $B B C$ and Reuters have gone on the counter-offensive, emphasising their commitment to fact-based journalism and key tenets of the normative objectivity paradigm - accuracy, impartiality and freedom from bias. This paper rehearses briefly this debate, reviews challenges to normative values and the recent fight back in the United Kingdom and United States in the wake of fake news. But are there other disruptive factors ushered in by social media that are challenging norms from within established news organisations, irrespective of their public adherence to the traditional objectivity norms? Drawing on a conceptual framework of boundary work (Carlson \& Lewis 2015; Gieryn 1999) and anonymised semi-structured interviews with journalists at leading legacy news outlets, the paper specifically investigates how journalists perceive the impact of two changes to practice that have now become commonplace in newsrooms. Firstly, it explores the growing requirement for journalists to use Twitter and similar social media tools to promote their own news output or their news organisation; and secondly it examines the introduction of social media 'hubs' in which journalists trawl the Internet for user-generated content to complement their own (often video or still images, over and above that flowing across Twitter). To what extent are these two practices, conducted from within the walls of a news organisation actively espousing normative values of objectivity, actually changing journalists' perceptions of their role and the culture of the newsroom? And does this mean that the once monolithic culture of news and the broadly consensual view of professional ideology are becoming more diffuse? 


\section{The objectivity paradigm - challenges and counter-challenges}

The origins of Anglo-American journalism's normative values have been well rehearsed and reflect a confluence of factors in the late $19^{\text {th }}$ Century and early $20^{\text {th }}$ Century rather being the product of one "magical moment" (Schudson 2001: 167). Journalists were keen to establish a profession distinct from the emerging discipline of Public Relations; the development of mass newspaper printing prompted owners to sell more copies by making their news less partisan and open to more readers; the invention of the telegraph led to a clipped news style with facts at the top in case stories were cut off by technical failure. By the 1930s, the concept of objectivity had become well established on both sides of the Atlantic and, whether advocated or criticised, it has retained a central place in debates over journalism up to the current day (Maras 2013: 5). In practical terms, core components of the objectivity paradigm identified by Mindich (1988) - detachment, non partisanship, the inverted pyramid style of writing, reliance on facts and balance - represent a common set of practices that constitute a professional ideology. Deuze observes how journalists have tended to benchmark their actions and attitudes self-referentially, seeing themselves as providing a public service, working autonomously, being objective, fair and therefore trustworthy (2005).

But no sooner were the foundations laid, than challenges emerged from a combination of journalists, academics and external forces (Maras 2013: 54; Schudson 1978). The Vietnam War and Cold War raised questions about whether journalists in their quest for balance were simply parroting government propaganda. Writers such as Norman Mailer, Joan Didion and Tom Wolfe mounted a brief challenge with what was called 'New Journalism' in the 1960s and 70s, trying to combine elements of traditional journalism with fiction. Of far greater lasting impact was deregulation of the U.S. broadcasting market in 1987 which paved the way for partisan channels such as Fox News and its liberal leaning counterpart $M S N B C$ (plus assorted American 'shock jocks' on radio). Such a development was unthinkable in UK broadcasting, given the remit and regulation of public service broadcasters such as the $B B C$ and $I T V$ although that did not stop British newspapers developing along party political lines. The inexorable rise of social media, particularly Google and Facebook, over the past decade has effectively divided journalists and academics into two camps: those who 
highlight the benefits of close co-operation and co-creation between legacy journalism and new forms of media (Allan 2013; Jenkins 2006; Bruns 2003, 2011) and those who argue that journalism's democratic role is being undermined (Currah 2009; Davies 2009; Phillips 2012). The first camp emphasises the porous nature of professional boundaries in today's social media ecology, diving head first into the chaos (Deuze \& Witschge 2017: 2). The second camp attempts to make those boundaries more impenetrable than ever, rallies the troops and closes ranks (ibid).

With the advent of fake news, there are signs of a shift in the weight of argument as some of the legacy news outlets go on a counter offensive to highlight the normative values of fact-based journalism and verification. Nowhere was this more clearly demonstrated than in submissions to a UK parliamentary inquiry ${ }^{2}$ into fake news. The $B B C$ highlighted its 'Reality Check' team, now expanded to investigate deliberately false news, while organisations such as the Press Association, ITN and Guardian News \& Media (the publisher of The Guardian and The Observer newspapers) all put store by the need to support long-standing values of transparency, fact-based journalism and verification (Culture, Media \& Sport committee, parliamentary inquiry, 2017). Alessandra Galloni, the global news editor of Reuters, which did not make a submission to the inquiry, said she believed the future of news was to "go back to the future."

"By back to the future, I mean the old-fashioned, boots on the ground, factbased reporting that is at the very heart and core of our profession," Galloni told a conference of student journalists in July $2017 .^{3}$

\section{Twitter and UGC become part of the daily routine of the newsroom}

This torrid period of fake news, populist rhetoric and partisanship has therefore left the battle lines hardened. But that is not to say that newsrooms, even though they are within traditional news organisations that are overtly espousing the values of objectivity, are not engaging in practices that from the bottom up challenge those

\footnotetext{
2 The inquiry was set up in January 2017 and closed in May following announcement of a snap general election.

${ }^{3}$ Future News, Edinburgh July 6-7, 2017.
} 
values. This section of the paper reviews existing academic literature that has focused on the use by journalists of Twitter and user-generated content. Both have become ever-present components of everyday life in the newsroom.

The online messaging and social networking tool Twitter, which restricts 'tweets' to 140 characters $^{4}$, was launched in 2006 . After a period of slow growth in the early years, Twitter was the largest source of online news on the day of the 2016 U.S. election and has rarely been out of the headlines since given President Trump's predilection for early morning tweets, some of which have included policy announcements and, often, are worthy of news stories (Isaac \& Ember 2016). By 11 a.m. on election day there were 27,000 election-related tweets per minute (ibid). About 500 million tweets are sent each day worldwide. In newsrooms, Twitter has been rapidly adopted as an essential mechanism for the distribution of breaking news and as a tool to solicit story ideas, sources and facts (Hermida, 2010: 299). It is in fact the most widely used social media tool by journalists (Parmelee 2013). In analysing Twitter as an example of micro-blogging practice by journalists, Hermida coins the term 'ambient journalism', drawing on the phrase 'ambient news' used by Hargreaves (2003) to describe a media landscape and society that is saturated with news. As such, Twitter is typical of a range of social media technologies that enable the disintermediation of news, allowing citizens to disseminate their own information and thus undermining the gate keeping role of journalists. The growing body of academic literature on Twitter in relation to journalism practice has tended to concentrate on two main issues: questions of fact, rumour and verification; and, more fundamentally, implications for the practice of journalism and its traditional norms. This paper explores how journalists themselves perceive the use of Twitter and specifically their use of it to promote their own work and news organisation. On the face of it, this does not seem to be a major concern to some journalists. One survey of Western journalists conducted by the Reuters Institute for the Study of Journalism found that $86 \%$ thought that they will have to engage in personal branding through social media, blogs, public appearances, etc. to succeed professionally in the future (2015). One early career television journalist was quoted as saying:

"I think journalists are developing their own brand that they market through

\footnotetext{
${ }^{4}$ Twitter announced in September 2017 that it was testing 280-character tweets.
} 
their work over devoting themselves to one news organisation."

But there are also journalists and academics who have voiced concern about the ethical challenges posed by Twitter. As Posetti observes (2009), many changeresistant journalists view Twitter as threatening and dangerous, arguing that it is a tool that undermines professional journalism. In their study of 'professional' journalists' views of citizen journalists and other writers online, Fenton and Witschge (2011) concluded that many see such content as 'bad' journalism where opinion masquerades as fact. Journalists are determined to guard the borders of their profession and demarcate where journalism ends and something else begins. They consider their output to be more valuable than that of non-professional news producers because they provide 'reliable' and 'factual' information in contrast to opinion and vitriol (ibid: 156). In the study, blogs were characterised as inaccurate and lacking the balance a newspaper provides. News organisations have reacted defensively by issuing guidelines on the use of Twitter, keen to protect their existing rules. Deuze and Witschge (2017: 11) highlight one of those dilemmas by describing how changing practice is breaking down the traditional wall between the commercial and editorial sides of news organisations. In this environment, the news business demands that its workers increasingly shoulder the responsibility of the company (ibid). Indeed, many organisations now expect their journalists to routinely tweet, as often as not to promote their own news outlet and to direct users back to their main website (Vis 2013: 29). This paper explores the implications of such behaviour for the 'Chinese wall' that has traditionally separated editorial and commercial considerations.

At a time when the media debate is dominated by fake news, coupled with a resurgence of interest in issues of verification and fact-based journalism, it is hardly surprising that journalists and academics have pointed out the potential dangers of overreliance on Twitter and its potential to spread gossip, rumour, and falsehoods. This in turn leads to scepticism from journalists, reflecting their unease in adopting a platform which appears to be at odds with journalism as a professional discipline based on the concept of verifying information (Hermida 2010: 300). Verification has been characterised as the "essence of journalism" (Kovach \& Rosenstiel 2001: 71) - it was in this spirit that in 2017 the BBC expanded the remit of its 'Reality Check' team of journalists to tackle fake news emanating from social media, specifically in the 
wake of public concern over reporting of the 2016 U.S. election campaign and UK referendum on membership of the European Union. It is not just the emergence of Twitter as a source of breaking news but also the speed at which information is disseminated that is placing increased strain on established journalistic practices (Hermida 2012: 661). This in turn has led some academics to suggest that the practice of journalism, and the relationship between journalists and their sources, is inevitably changing as part of what Broersma and Graham call a "convenient marriage", with Twitter becoming an established 'beat' in it own right, displaying both physical and social qualities ((2013: 446-447). Their study of Twitter use by journalists between 2007-2011 in Britain and the Netherlands found it enabled them to keep in touch with their beat, approach people for comment and information, follow specific topics and integrate tweets as quotes into their news stories. In addition, the study showed that in about $20 \%$ of the stories in which tweets were quoted, this led to a further story (because the tweet itself was considered to be newsworthy). The relatively new practice of citing tweets in stories makes news coverage more diverse but, at the same time, taking these tweets at face value erodes journalism as a practice of verification (ibid: 461).

The most fundamental debate, however, is whether social media tools such as Twitter are in fact bringing lasting change to journalistic norms and, above all, the core concept of objectivity. Through merging the professional with the personal (as journalists use Twitter as a reporting tool but also tweet their own views and become participants in debates), the use of such social media blurs the traditional lines or boundaries (Posetti 2009). Reporters' use of the Twitter platform to express their own views and opinions raises red flags about professional conduct and bias (ibid). As Singer argues, the fluidity of information on Twitter means that material produced by journalists mingles in myriad ways with material produced by users, shifting the emphasis towards verification and transparency and lessening the importance of traditional norms such as objectivity (2015: 29). A study by Vis into two prominent journalists who were tweeting during the four-day summer riots that hit the United Kingdom in 2011 remarked on the ease with which opinion was included in tweets, highlighting the watering down of an established journalistic norm (2013: 43). The Guardian's Paul Lewis inserted his opinion into 5.2\% of his tweets, while in the case 
of Ravi Somaiya of The New York Times this rose to $22.4 \%$. This, she suggested, could give rise to a new hybrid norm on Twitter (2013: 44).

Twitter is, of course, one form of user-generated content but much of what is now routinely monitored in newsrooms extends way beyond that, consisting of material from blogs, a host of other social media platforms, plus videos and still images uploaded by the public. What began as a trickle of content has turned into a veritable torrent, prompting many of the larger legacy news organisations to set up 'social media hubs' to sift through the additional content. The value of user-generated video and images came to prominence with the Asian tsunami in December 2004 when holiday makers provided dramatic footage of tidal waves sweeping ashore. But it was the July 7 London terror bombings of 2005 which prompted the BBC to set up its hub, one of the first organisations to do so. Helen Boaden, who was the BBC's Director of News at the time, identified the attacks as a watershed and "the point at which the BBC knew that newsgathering had changed forever" (2008). She wrote:

"Within 24 hours, the BBC had received 1,000 stills and videos, 3,000 texts and 20,000 e-mails. What an incredible resource. Twenty-four hour television was sustained as never before by contributions from the audience; one piece on the Six O'clock News was produced entirely from pieces of user-generated content. At the BBC, we knew then that we had to change. We would need to review our ability to ingest this kind of material and our editorial policies to take account of these new forms of output."

The explosion in the volume of images and video - sometimes of a graphic and disturbing nature - has been accompanied by the speed of their circulation, not least by their inclusion within the various outlets of professional news organisations. The opportunities and threats of such images have been well rehearsed in academic literature over the past decade. On the one hand, they provide coverage of events the consumer of news would otherwise never have seen and often in real time (Allan 2013); they provide an inexpensive opportunity for news organisations to intensify their links to their customers and generate engagement at a time of economic pressure on the industry (Pantti \& Baker 2009); the fact that they are not edited or digitally enhanced can make the impersonal detachment of mainstream news photography and 
journalism's preferred framing seem outmoded (Allan 2014); in this sense, such material is considered by the public to be "more real and less packaged", adding drama and human emotion to an otherwise dry news environment (Williams et al. 2011). But on the other hand, there are concerns whether such images are foregrounding highly emotive content and whether their affective impact is watering down objectivity norms. In addition, terrorist organisations such as ISIS have adopted an aggressive social media strategy, enabling their graphic propaganda images to gain traction in established media. As Linfield notes (2015), what she calls the "perpetrator image" or "terrorist selfie" is now being used to celebrate acts of violence:

"We live in the age of the fascist image. The cell-phone camera and lightweight video equipment - along with YouTube, Facebook, Instagram, and all the other wonders of social media - have allowed perpetrators of atrocities to document, and celebrate, every kind of violence, no matter how grotesque."

Beckett and Deuze (2016: 1) go so far as to say that the challenge for today's news industry is to be meaningful, insightful and trustworthy in what they term an "emerging affective media ecosystem." In this paper, based on interview data, I argue that we are witnessing a subtle shift in the practice of journalism as the immediacy of social media content and what is termed a 'new visibility' (Thompson 2005) afforded by mobile technology becomes all-pervasive. While many journalists working on social media hubs still adhere in public to the shared rituals of objectivity, there are signs that the impact of user-generated content is spilling over into the wider newsroom culture and having a contagious impact on practice in the broader news environment.

\section{Methods}

This research set out to explore three main questions related to the use of Twitter and user-generated content: firstly, whether such the use of such tools is blurring the traditional journalistic boundaries between the professional and private; secondly, whether current practice of use is changing adherence to the objectivity norm; and thirdly, if this is the case, whether some normative values are being upheld and others undermined. In-depth interviews were conducted with 12 journalists working for 
mainstream news organisations in the United Kingdom. All of those selected used Twitter as a tool in their daily work as a journalist and the majority also handled usergenerated copy, some working shifts on social media hubs in the newsroom. All the interviews were anonymised because of the sensitive nature of some of the material.

The research did not analyse the actual 'tweets' sent by the journalists but focused instead on how they perceived the use of Twitter in practice. Questions sought to ascertain the extent to which they injected their own opinion into tweets and whether they used Twitter as an interactive tool (engaging the audience in a two-way exchange, or whether use is generally limited to one-way communication from the journalist). In exploring interactivity, the research drew on work by Parmelee et al. (2017: 4) who examined the prevalence of three features of Twitter among U.S. political reporters: the retweet, @mention and @reply. The retweet allows the journalist to include his or her own message to the originator of the tweet but is generally unlikely to lead to a conversation. The @mention can work as a link but also as an invitation to conversation. The @reply function is the most direct and common way to start a conversation. Questions about the interactivity of Twitter use are relevant because they can gauge a journalist's willingness to reassess the traditional one-way relationship to the audience that prevailed in the news landscape before the advent of social media. Questions about Twitter use also sought to ascertain journalists' opinion about personal branding that can follow from developing a high profile on the platform, and about the expectations of newsroom managers. Journalists were asked whether the volume of their tweets is monitored and whether Twitter use forms part of a job description or job evaluation.

The handling of user-generated content flowing into a newsroom from third parties raises somewhat different questions but ones that also go to the heart of the blurring of lines between journalistic norms of, for example in this case gate keeping, and an evolving practice of 'curating' a wider choice of content that has not been produced solely by established journalists. Questions here focused on what can often be the emotive content of graphic user-generated images and video designed as propaganda and whether that might in turn be leading to a contagious impact on the wider news file, undermining traditional values of fact-based journalism. Equally, the interviews explored to what extent journalists are coming under pressure to move a story more 
quickly than normally based on social media content without originating or checking the news themselves. Both gate keeping and verification are classic normative behaviours associated with the objectivity paradigm. As Hermida observes, verification is a core normative practice, defining professional behaviour and serving as a boundary to differentiate the occupational 'turf' of journalism from other forms of communication (2015: 38).

\section{Findings: working with Twitter}

Mainstream news organisations point out publically that they expect journalists to adhere to the same rules of practice when engaging with social media tools such as Twitter as in their more traditional journalistic work. The BBC's guidance to its journalists (2010), freely available online, makes it clear that they are expected to "behave appropriately when on the Internet, and in ways that are consistent with the BBC's editorial values and policies." The guidelines state:

"Impartiality is a particular concern for those working in News and Current Affairs. Nothing should appear on their personal blogs or microblogs which undermines the integrity or impartiality of the BBC."

One BBC editorial manager interviewed for this paper said:

"We don't tell people or expect our journalists to tweet in order to promote the brand. Of course, there are times when they are drawing attention to a piece of work they are pleased with, but that's a different thing."

The international news agency Reuters takes a similar line. In its guidelines to staff, also drawn up in 2010, Reuters highlights how social media has been "a great boon" for the practice of journalism and opened up new ways to report and transmit. The guidelines warn, however, that social media is full of potential pitfalls and that there should be no different code of practice relating to, for example, microblogging on Twitter: 
'When writing as Reuters journalists, whether for the file or online, we are guided 24 hours a day by the ethics of our organisation as embodied in the Code of Conduct and the Trust Principles, which require us to be responsible, fair and impartial."

The simple act of 'liking' a post or joining an online group can compromise those standards, Reuters says. It spells out the dilemma and dangers:

"The tension is clear: Social networks encourage fast, constant, brief communications; journalism calls for communication preceded by fact-finding and thoughtful consideration. Journalism has many 'unsend' buttons, including editors. Social networks have none. Everything we say online can be used against us in a court of law, in the minds of subjects and sources and by people who for reasons of their own may want to cast us in a negative light."

The latest major player to update its guidelines is The New York Times which, in a note to its editorial staff, warned that journalists need to take extra care to avoid expressing partisan opinions or editorialising on issues the paper is covering, adding: "violations will be noted on performance reviews." Its guidelines published to the public in October 2017 state:

"Social media plays a vital role in our journalism. On social platforms, our reporters and editors can promote their work, provide real-time updates, harvest and curate information, cultivate sources, engage with readers and experiment with new forms of storytelling and voice.

"We can effectively pull back the curtain and invite readers to witness, and potentially contribute to, our reporting. We can also reach new audiences.

"But social media presents potential risks for The Times. If our journalists are perceived as biased or if they engage in editorializing on social media, that can undercut the credibility of the entire newsroom."

These examples from the BBC, Reuters and most recently The New York Times are typical of the way mainstream news organisations have attempted in the recent past to 
regulate their journalists' use of social media and to normalise it within existing editorial guidelines. As if to underline this, some news outlets insert their brand into the twitter 'handle' or name of the journalist - e.g. @BBCcorrespondentname, or @ITVcorrespondentname.

How then do journalists perceive the use of a social media tool such as Twitter and what is their actual practice when confronted with a fast moving news story? Clearly expectations have changed and Twitter is now fully integrated into newsrooms, not least as a tool to gather and disseminate news. As such it is increasing the pressure on journalists to engage in multi-tasking and arguably adding to the stress of the job. In fact, interviewees told how their working day often started in the early morning, at the office or increasingly at home over breakfast, with them checking Twitter and other social media messaging apps such as WhatsApp and Facebook Messenger. As one senior reporter at a major newspaper said:

"Every journalist has a smart phone and that is now your main journalistic tool, more important than your notebook, and the first thing you do in the morning is look at Twitter ... what you are looking for are not what the 'punters' are saying about the news but direct messages - the use of Twitter as a networking tool is probably the most important thing we have."

This normalisation of Twitter has had clear consequences for the daily routine. It has effectively extended the job into an 'always on' environment and it means the phone rings less in the office. Contacts for their part appear to like using Twitter as a form of direct communication since they have a clear record of what they are saying to reporters in case of dispute. Although on the face of it a transparent tool, in the United Kingdom Twitter and other messaging apps have allowed reporters to quietly maintain one-to-one contacts with officials - particularly the police - in a way that has become difficult in public since the 2011-12 Leveson Inquiry into the press. ${ }^{5}$ These tools have also allowed journalists to bypass press departments and the gate keepers who shield officials, companies and politicians from the press.

\footnotetext{
${ }^{5}$ The Leveson Inquiry, instituted by then Prime Minister David Cameron to investigate allegations of phone hacking by journalists, recommended that contact between the police and press should be formally reported.
} 
Some journalists interviewed readily accepted that tweets sent out by someone to a group of 'followers' could be used as quotes in their stories. As Broersma and Graham observed in their study of Dutch and British newspaper reporters, taking tweets at face value without contacting the source tends to erode journalism as a practice of verification (2013: 461). However, some interviewees said their newspapers are less willing to do so for print stories and that they are now also pasting screen grabs of tweets into a rolling story as it unfolds online. This in turn suggested there is one set of (traditional) rules for print and one set (of new rules) for online, even within the same organisation. One reporter said he felt the practice of pasting a tweet into an online story actually increased the transparency of the news process for the public, "keeping journalism on its toes" at a time when trust of the media has sunk to all-time lows. Others recounted how they routinely tweeted out to the public the blow-by-blow account of court proceedings, effectively becoming an agency journalist. At the end of a day's court hearing, the outgoing file of tweets formed the raw material for a traditional written story. According to one journalist who routinely tweeted from the courtroom, that can also cause problems - it is not always possible to tweet and take a comprehensive note at the same time, meaning the raw material for the final report was sometimes lacking in detail.

Journalists were more sceptical when it came to using Twitter in general messages to their 'followers', acknowledging potential conflict with their deeply embedded cultural norms. Most UK newspapers now expect and encourage their journalists to tweet and build a personal brand, sometimes as an expert in their field and not least to help drive traffic to their websites. Few require it, but some of the reporters interviewed said they were aware that their use was being monitored by editorial management and, in some cases, the number of their 'followers' on Twitter was being measured. The editorial manager of one editorial group interviewed for this research paper was keen to stress that they were not asking journalists to step over normal boundaries by developing a profile on Twitter:

"They are drawing attention to themselves, drawing attention to the brand, magnifying the audience and building a community of interest ... there is a 
sacred line, we would not succumb to tweeting marketing messages but they will tweet things that will attract people to the brand," he said.

"The legacy media are in a battle to survive - and it behoves everybody, without crossing that sacred line, to chip in where they can, so not being commercial but helping to promote. It is absolutely legitimate to do it, if we don't survive as a business, there will be no journalism and there will be no integrity or anything else. It is in all our interests to survive while retaining the ethical standards the brand adheres to. Everybody now is buying in, even the non-digital natives."

One young reporter, who had graduated from an undergraduate journalism course a year earlier, said she felt promoting her own stories, and by extension the news outlet, was now the norm, saying: "I always feel I should be promoting the people I work for, I want to see the web site doing well, I don't really feel I am crossing the line ... I am doing what is expected of me."

In practical terms, Twitter has effectively meant that reporters have lost their relative anonymity and developed a personal 'brand' much in the same way that has for many years been standard for senior television reporters or star columnists.

"Even news reporters have developed their own individual brands and this is problematic in lots and lots of ways," said one senior newspaper reporter.

"One of the things that Twitter makes difficult is to be that old fashioned news gathering journalist who has some kind of notion of ... impartiality ... or a notion that you will be as fair and accurate as you can be ... that myth has been destroyed by Twitter to some extent."

This is not, he argued because journalists themselves are necessarily consciously crossing a line into biased journalism but because the public body of Twitter users can be deeply partisan (about issues such as Brexit and Trump) and therefore assume that journalists they are communicating with shares that new partisan culture. Just by retweeting political comments, a journalist risks being seen as endorsing the view 
expressed. The New York Times emphasised this in its newly published guidelines, saying that although journalists may think their Facebook page or Twitter feed is a private zone, everything they post or 'like' online is to some degree public. In shrinking newsrooms, the lines between news reporters and columnists who are commentating on, for example, politics have already become more blurred. As one senior newspaper reporter observed, Twitter is the front line in the battle of two cultures, the journalistic culture and the partisan culture. And they are clashing uncomfortably in the electronic battlefield that is today's social media environment. The need to summarise the main point of a column in a 140-word tweet has led to a further erosion of nuanced arguments in favour of blunter statements that can also overstep the normative boundaries of journalism. The use of Twitter to promote stories to a journalist's followers is typically a one-way communication. Some said they did use Twitter as an interactive tool but that they were also wary of being sucked into partisan conversations where the tone can quickly become aggressive. That in turn could be re-used in a populist, partisan environment to attack mainstream journalism.

\section{Findings: working with user-generated content}

Using the example again of the BBC and Reuters, legacy news organisations have adopted the same normative attitude to user-generated content. The BBC acknowledges in its guidelines to journalists the important role that citizen generated content now plays in its reporting of the news. But it also is at pains to point out that the rules remain the same:

\footnotetext{
"Our starting point is that we should aim to apply the same approach ${ }^{6}$ to pictures, audio and video supplied by members of the public, as we do to any other material we handle as journalists. We should not automatically assume that the material is accurate and should take reasonable steps where necessary to seek verification."
}

This is echoed by the Reuters internal guidelines:

\footnotetext{
${ }^{6}$ The author's italics.
} 
"The same standards of sourcing, identification and verification apply. Apply the same precautions online that you would use in other forms of newsgathering and do not use anything from the Internet that is not sourced in such a way that you can verify where it came from. “

When it comes to working with user-generated content in practice, the journalists interviewed were clearly aware of the opportunities and, at the same time, of the new threats afforded by user-generated content. Indeed, it is hard to think of today's news coverage without focusing on the all-pervasive nature of digital video or images. They become engraved in our mind as readers and viewers of the news, whether they be scenes from the horror of Middle East conflict, terror on the streets of London or the devastation wrought by natural disasters. The establishment of the BBC's social media hub referred to earlier in this paper is testimony to the normalisation of such content, its inclusion and acceptance into the news process. The journalists working on social media desks are often young, inexperienced and see the position as the first rung on the ladder as they try to identify newsworthy content and establish themselves in a news organisation. One junior producer at a broadcaster had been hired largely for her social media skills and spent the bulk of the day sifting through material emanating from the Middle East. The constant diet of gruesome images and footage had by her own admission a clear emotional impact on her. During one particularly intense period of news, she noticed how she was becoming more and more withdrawn. She said:

"Some days, it would not affect me at all and I'll just get on and it's fine, doing stuff. And then ... surprise, surprise, towards the end of the week, I would start feeling more and more down and upset and just really more or less anti-social. I think I became a lot more withdrawn and didn't really want to speak to as many people."

In fact, there is growing recognition that emerged through my interviews that such content could have an addictive and damaging affect on the journalists monitoring it. While the risks associated with covering conflict or disasters abroad are well known, the newsroom back home had been considered a 'safe zone'. But today it can also be a site of stress and even trauma. The concern expressed in interviews echoed the 
findings of a 2015 survey of journalists working with user-generated content by Eyewitness Media Hub which classified such social media desks as 'the new digital frontline' (2015: 16):

\begin{abstract}
"Office-bound staff who used to be somewhat shielded from viewing atrocities are now bombarded day in and day out with horrifically graphic material that explodes onto their desktops in volumes, and at a frequency that is very often far in excess of the horrors witnessed by staff who are investigating or reporting from the actual frontline."
\end{abstract}

The interviews also brought out the perception from journalists that such content is also having a contagious impact on the wider newsroom, echoing Beckett and Deuze's observation that the news media are becoming more emotionally driven (2016: 5). In a broadcast environment, one senior producer commented how the graphic nature of images from the Middle East conflict has spilled over from the intake desk into general newsroom environment and may be unconsciously affecting editorial decisions about what content to use. Also in a newspaper environment, it seems that social media, and particularly images, can quickly influence editorial practice and spread contagiously to influence the normal culture. One senior news reporter told how she had come under pressure from the news desk to produce a story on a breaking terror attack on the basis of social media content without gathering her own information. She believed news desks can become wrapped up in social media content to the extent that sometimes the "tail starts wagging the dog." In this case, she came under pressure to write a story based on the breaking video and Twitter feeds, rather than standing back on the story and check the facts of what had happened.

"Social media has made everything so much faster ... there's so much video around and it almost desensitises you in a way. So much of it," she said. "... I think the public could get, you know, immune to the images in a way. It's almost like you need more and more horror or more and more graphic detail to make an impact." 


\section{Conclusion}

There was no evidence from those journalists interviewed that their commitment to the objectivity paradigm and its values had been overtly broken. Indeed, many of them highlighted their awareness of what they saw as the risks that can accompany the use of social media. But at the same time, their description of practice did suggest that key elements of that paradigm are being challenged and at times eroded, albeit subtly and unconsciously from within.

From the top down, editorial managers at legacy news organisations have been at pains to contain social media tools within their normative framework, going to great lengths to issue guidelines, differentiate between professional and personal use (for example by requiring Twitter handles that indentify the news organisation clearly) and to ensure that they retain a measure of control over third party material. As such, they have been keen to maintain their traditional role of gate keeping and to normalise use of social media as part of the everyday job of a journalist. It is a classic example of journalists engaging in boundary work to establish and enlarge journalism's institutional authority (Deuze \& Witschge 2017: 4).

But in practice, and from the bottom up, journalists are entering into territory that blurs the lines and is fragmenting the once monolithic culture of objectivity. Those interviewed were comfortable using Twitter as an everyday reporting tool, making contact with sources, circumventing a recent trend for greater transparency in contact with officials (for example, the police) and making it part of their everyday routine. But the lifting of quotes directly from Twitter into online stories is a practice that does threaten to undermine the core journalistic value of verification. This practice appeared to be acceptable for an online story but less so for a newspaper's print version, suggesting that traditional and emerging new standards coexist. In tweeting themselves, some journalists were nervous about being sucked into a partisan and populist environment in which it can be hard to maintain an impartial or detached stance. Some cited examples of how Twitter could increase transparency in the newsgathering process, but others felt that promoting their own name blurred the line between being a journalist and was coming close to engaging in marketing activity. There were also signs that the increased volume of user-generated content flowing 
into the newsroom is having two disruptive effects that are challenging norms - it is increasing the emotive nature of news and it is driving the file at a speed that at times means stories cannot be properly verified before publication. On the face of it, the narrative of objective journalism appears to be intact. But it is a delicate balancing act. On the ground, social media is acting as a catalyst that is diluting and fragmenting the once coherent entity that was the newsroom and is redefining practice. 


\section{References}

Allan, Stuart (2013), Citizen Witnessing: Revisioning Journalism in Times of Crisis, Cambridge: Polity Press.

Allan, Stuart (2014), Witnessing in Crisis: Photo-reportage of terror attacks in Boston and London. Media, War \& Conflict, 7 (2), pp 133-151.

Anderson, C.W., Bell, Emily. \& Shirky, Clay (2014), Post industrial journalism: adapting to the present. New York: Tow Center for Digital Journalism.

BBC editorial guidelines. Available from:

http://downloads.bbc.co.uk/guidelines/editorialguidelines/pdfs/Editorial_Guidelines_i $\underline{n \text { full.pdf }}$

BBC guidance note on user-generated content. Available from:

http://www.bbc.co.uk/guidelines/editorialguidelines/assets/advice/user_generated_con tent.pdf

BBC guidelines on social media use. Available from:

http://www.bbc.co.uk/editorialguidelines/guidance/social-networkingpersonal/guidance-full\#heading-social-networking-sites

Beckett, Charlie and Deuze, Mark (2016), On the Role of Emotion in the Future of Journalism. Social Media + Society, 2 (3), 2056305116662395.

Boaden, Helen (2008), The role of citizen journalism in modern democracy. The BBC (online), 13 November 2008. Available from:

http://www.bbc.co.uk/blogs/legacy/theeditors/2008/11/the_role_of_citizen_journ alism.html

Broersma, Marcel and Graham, Todd (2013), Twitter as a news source. How Dutch and British newspapers used tweets in their news coverage, 2007-2011. Journalism Practice, 7 (4), pp 446-464. 
Bruns, Axel (2003), Gatewatching not Gatekeeping: Collaborative online news. Media International Australia Incorporating Culture and Policy: Quarterly Journal of Media Research and Resources, 107, pp 31-44.

Carlson, Matt and Lewis, Seth (2015), Boundaries of Journalism: Professionalism, Practices and Participation, London: Routledge.

Culture, Media \& Sport Committee, 2017. Fake news inquiry, available from: https://www.parliament.uk/business/committees/committees-a-z/commonsselect/culture-media-and-sport-committee/inquiries/parliament2015/inquiry2/publications/

Currah, Andrew (2009), What's happening to our news? Oxford: Reuters Institute for the Study of Journalism.

Davies, Nick (2009), Flat Earth News, London: Vintage.

Deuze, Mark and Witschge, Tamara (2017), Beyond Journalism. Theorizing the transformation of journalism, Journalism, https://doi.org/10.1177/1464884916688550.

Eyewitness Media Hub, 2015. Making Secondary Trauma a Primary Issue: A Study of Eyewitness Media and Vicarious Trauma on the Digital Frontline.

Available from: http://eyewitnessmediahub.com/research/vicarious-trauma

Fenton, Natalie and Witschge, Tamara (2011), Comment is free, facts are sacred: journalistic ethics in a changing mediascape. In G. Meikle and G. Redden (eds) News Online - Transformation and Continuities, Basingstoke: Palgrave Macmillan.

Gieryn, Thomas (1999), Cultural boundaries of science: Credibility on the line, Chicago: University of Chicago Press.

Hermida, Alfred (2010), Twittering the news. Journalism Practice, 4 (3), pp 297-308, 
Hermida, Alfred (2012), Tweets and trut. Journalism as a discipline of collaborative verification. Journalism Practice, 6 (5-6), 659-668.

Isaac, Mike and Ember, Sydney (2016), For election day influence, Twitter ruled social media. The New York Times, 8 November 2016. Available from: https://www.nytimes.com/2016/11/09/technology/for-election-day-chatter-twitterruled-social-media.html

Jenkins, Henry (2006), Convergence culture: where old and new media collide. New York: New York University Press.

Kovach, Bill and Rosenstiel, Tom (2001), The Elements of Journalism: what newspeople should know and what the public should expect. London: Random House.

Linfield, Susie (2015), Perpetrator Images of Atrocity and Suffering: Then and Now. In: The Visual Politics of the Human Images in Humanitarian and Human Rights Communication. London: London School of Economics.

Maras, Steven (2013), Objectivity in Journalism, Cambridge: Polity Press.

Mindich, David (1998), Just the Facts - How Objectivity came to define American Journalism, New York: New York University Press.

New York Times guidelines on social media. Available from:

https://www.nytimes.com/2017/10/13/reader-center/social-media-guidelines.html

Pantti, Mervi and Bakker, Piet (2009), Misfortunes, sunsets and memories: nonprofessional images in Dutch news media. International Journal of Cultural Studies, 12, (5), pp 1-19.

Parmelee, John (2013), Political journalists and twitter: influences on norms and practices, Journal of Media Practice, 14 (4), pp 291-305. 
Parmelee, John, Nataliya, Roman, Beasley, Berrin and Perkins, Stephynie (2017), Gender and generational differences in political reporters' interactivity on Twitter. Journalism Studies.

Picard, Robert (2015), Journalists' perceptions of the future of journalistic work, Oxford: Reuters Institute for the Study of Journalism.

Phillips, Angela (2012), Old Sources: New Bottles. In N. Fenton (ed) New Media, Old News: Journalism \& Democracy in a Digital Age, London: Sage.

Posetti, Julie (2009), Twitter's difficult gift to journalism, Sydney: New Matilda.

Reuters guidelines on reporting from the Internet and using social media. Available from:

http://handbook.reuters.com/index.php?title=Reporting_From_the_Internet_And_Usi ng_Social_Media\#Using_Social_Media

Schudson, Michael (1978), Discovering the News - A Social History of the American Newspaper, New York: Basic Books.

Schudson, Michael (2001), The Objectivity Norm in American Journalism. Journalism, 2 (2), pp 149-170.

Singer, Jane (2015), Out of Bounds - Professional norms as boundary markers. In M Carlson and C Lewis (eds) Boundaries of Journalism: Professionalism, Practices and Participation, London: Routledge.

Snow, Jon (2017), Reporting on Grenfell made me feel on the wrong side of the social divide. The Guardian, 23 August 2017, available from:

https://www.theguardian.com/media/2017/aug/23/jon-snow-grenfell-mactaggartmedia-diversity

Thompson, John (2005), The New Visibility. Theory, Culture \& Society, 22 (6), pp 31-51. 
Vis, Farida (2013), Twitter as a reporting tool for breaking news, Digital Journalism, $1(1)$, pp $27-47$.

Williams, Andy, Wahl-Jorgensen, Karin and Wardle, Claire (2011), More real and less packaged: audience discourses on amateur news content and their effects on journalism practice. In K. Anden-Papadopoulos and M Pantti (eds) Amateur Images and global news, Chicago: Intellect, University of Chicago Press. 